Ahmet Akkuş

https://doi.org/10.21278/TOF.41407

ISSN 1333-1124

eISSN 1849-1391

\title{
NUGGET FORMATION EFFECTS IN RESISTANCE SPOT WELDED DIFFERENT STEEL SHEETS
}

\begin{abstract}
Summary
In this study, galvanized and austenitic stainless steel sheets were joined to each other by using resistance spot welding. The thicknesses of the galvanized steel and austenitic stainless steel are 0.93 and $1.03 \mathrm{~mm}$, respectively. The experiment parameters are the sheet combination and the weld nugget diameter. Three weld nugget diameters were selected, 4, 5, and $6 \mathrm{~mm}$, which are most widely used in the steel sheet joining industry. Pre-tests were performed to investigate the effect of the welding current on the nugget diameter. By using the pre-test results, series of resistance spot welded steel sheets were obtained with 4,5 and 6 $\mathrm{mm}( \pm 0.1)$ nugget diameters, in the combinations of galvanized - galvanized steel and galvanized - austenitic stainless steel. In the first step of main experiments, spot welded specimens were subjected to tensile tests, and the effect of the sheet combination on the maximal tensile strengths was discussed. In the last step of the investigation, macro photographs of the weld nugget between the steel sheets were taken. The effect of the sheet combination on the nugget formation was discussed and the relationship between the maximal tensile strength and the nugget formation was determined.
\end{abstract}

Key words: $\quad$ Steels, Joining, Resistance spot welding, Sheet combination.

\section{Introduction}

Resistance spot welding is a welding process which is widely used in manufacturing. This welding process is used at the most important levels of steel sheet structures and especially in automotive industry [1]. This type of welded joints is exposed to static and dynamic forces during the operation. Corrosion is one of the most important problems in the steel structures. To improve corrosion resistance, steel sheets are coated with zinc, and these zinc-coated steel sheets are called galvanized steel sheets. To decrease the cost and the height of the structure, resistance spot welding is used in manufacturing to join together not only sheets of the same material but also the sheets of different materials (for example, galvanized steel sheets and austenitic stainless steel sheets) [2]. Some problems may occur in spot welded sheets of different materials during operation; thus, it is very important to investigate these problems, for example the static strength of joints and the nugget formation between the sheets [3]. 


\section{Experimental Study}

\subsection{Welding Process}

In this experimental study, a commercial AISI 304 type stainless steel sheet and a galvanized HSLA (High Strength Low Alloy) steel sheet were used. The sheet materials were cut into specimens of $100 \times 30 \mathrm{~mm}$ and were joined as lap joints in three material combinations. The thicknesses of the galvanized HSLA and stainless steel sheets are $0.95 \mathrm{~mm}$ and $1.03 \mathrm{~mm}$, respectively. The nugget diameter of the spot welded joints varies between $4 \pm$ 0.1 and $6 \pm 0.1 \mathrm{~mm}$ in industrial applications. In order to obtain the relationship between the welding current and the nugget diameter, pre-tests were carried out. In these pre-tests, the welding current was changed from $5.5 \mathrm{kA}$ to $13.5 \mathrm{kA}$, with an increment of $0.5 \mathrm{kA}$. Table 1 gives the values of the applied currents for the investigated nugget diameters and Figure 1 shows a graph of the welding current versus the nugget diameter. During the spot welding operations, the welding time ( 15 periods), squeezing time ( 25 periods) and cooling time (25 periods) were kept constant ( 1 period $=1 / 50 \mathrm{sn})$.

Figure 1 shows that three welding times were selected to obtain 4,5 , and $6 \mathrm{~mm}$ weld nugget diameters in each sheet combination. The welded specimens prepared for mechanical and macro structural examinations are shown in Figure 2.

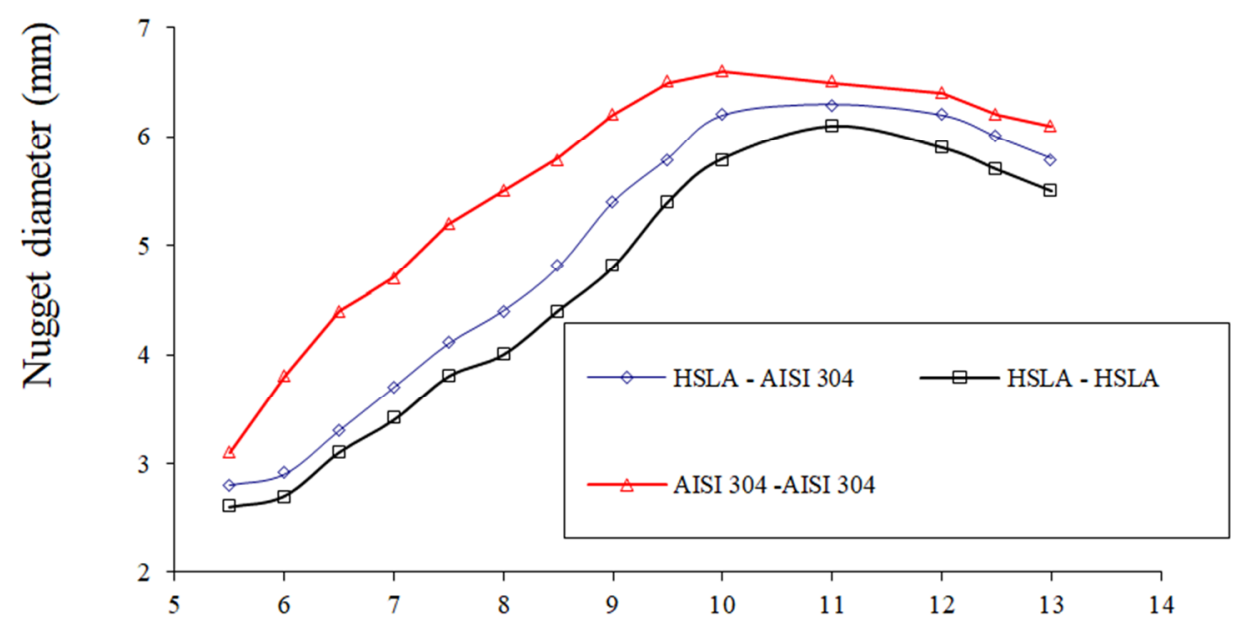

Welding current $(\mathrm{kA})$

Fig. 1 The welding current versus nugget diameter

Table 1 Applied currents for nugget diameters

\begin{tabular}{|c|c|c|}
\hline $\begin{array}{c}\text { Sheet } \\
\text { combination }\end{array}$ & $\begin{array}{c}\text { Nugget diameter } \\
( \pm 0.2 \mathrm{~mm})\end{array}$ & $\begin{array}{c}\text { Welding current } \\
(\mathrm{kA})\end{array}$ \\
\hline \multirow{2}{*}{$\begin{array}{c}\text { AISI304 - } \\
\text { AISI 304 }\end{array}$} & 4 & 6.25 \\
\cline { 2 - 3 } & 5 & 7.25 \\
\hline \multirow{2}{*}{$\begin{array}{c}\text { AISI 304 - } \\
\text { HSLA }\end{array}$} & 6 & 8.75 \\
\cline { 2 - 3 } & 4 & 7.25 \\
\hline \multirow{2}{*}{$\begin{array}{c}\text { HSLA - } \\
\text { HSLA }\end{array}$} & 6 & 8.75 \\
\cline { 2 - 3 } & 5 & 9.75 \\
\cline { 2 - 3 } & 5 & 8.1 \\
\hline
\end{tabular}


As shown in Figure 1 given above, when the welding current is increased, the nugget diameter increases until a critical current value. After that value, the nugget diameter decreases because of excessive melting and splashing. This is valid for all three material type combinations. Also, it can be said that the combination of two austenitic stainless steel sheets has the biggest nugget diameter if we consider the same welding current. Figure 2 shows a series of the spot welded specimens.

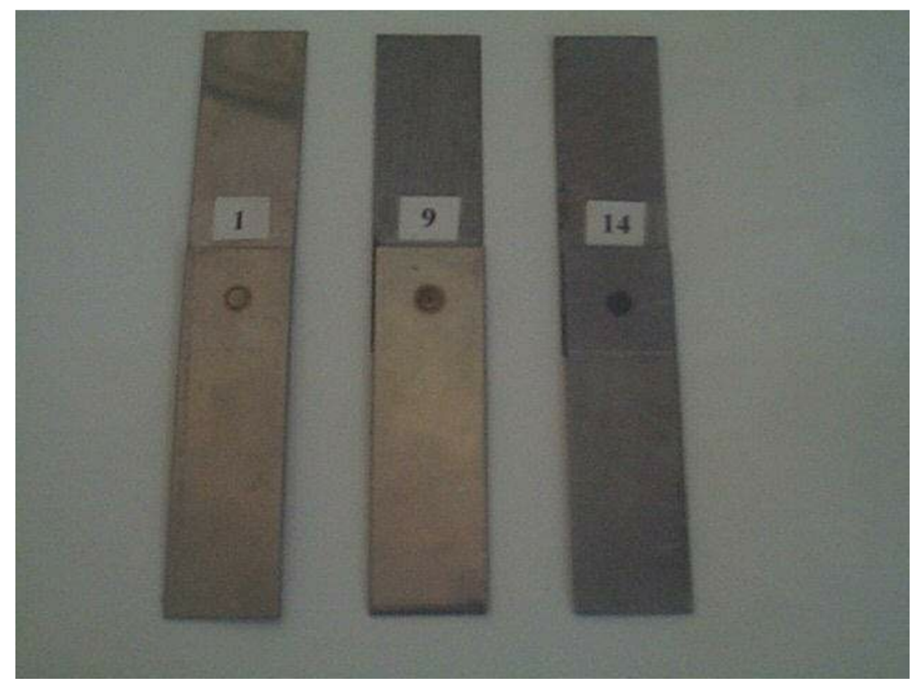

Fig. 2 A series of the spot welded specimens

2.2 Tensile Tests of the Two Types of Steel (AISI 304 and HSLA) and the Welded Specimens

The tensile test was done on the two types of steel (AISI 304 and HSLA). Their yield and tensile strengths obtained from the test are shown in Table 2.

Table 2 Mechanical properties of the two types of steel

\begin{tabular}{|c|c|c|}
\hline Material & Yield Strength (MPa) & $\begin{array}{c}\text { Tensile Strength } \\
(\mathrm{MPa})\end{array}$ \\
\hline AISI 304 & 326 & 667 \\
\hline HSLA & 345 & 620 \\
\hline
\end{tabular}

In the following step, the tensile tests were done to determine the tensile strength of the spot welded specimens and the effect of the nugget diameter on the tensile strength. Variations in the tensile strength of the spot welded specimens with respect to the nugget diameter are shown in Figure 3 for three types of sheet combinations. The rupture type of the welds zones between the steel sheets was buttoned up in each combination. 


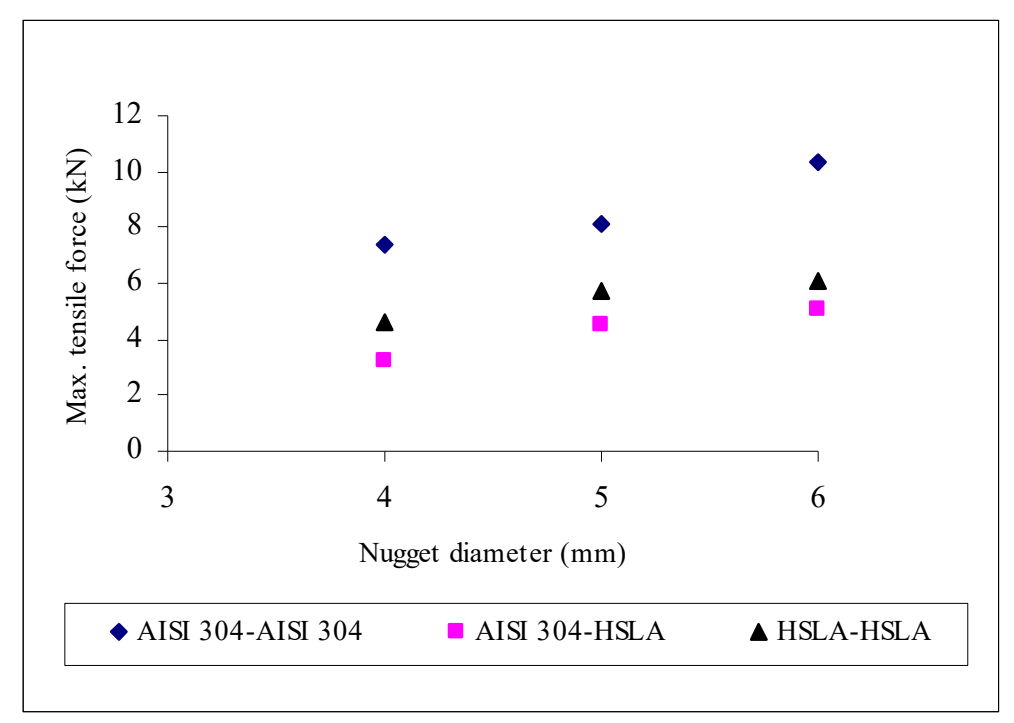

Fig. 3 The variation in the tensile strength of the spot welded specimens with respect to the nugget diameter

Figure 3 shows that while increasing the nugget diameter, the maximum tensile strength of the spot welded specimens also increases in each type of sheet combination. The AISI 304 - AISI 304 steel sheet combination has the highest tensile strength and the AISI 304 - HSLA steel sheet combination has the lowest tensile strength. According to the results read from the graph, it can be said that the nugget formation in the AISI 304 - HSLA steel sheet combination is not formed as balanced. To investigate this unbalanced formation between the sheets, the second series of the spot welded specimens was subjected to macroscopic examination.

\subsection{Macroscopic Examination of the Spot Welded Specimens}

A series of spot welded specimens with three different combinations of two steel types and 4, 5, and $6 \mathrm{~mm}$ nugget diameters were cut by a mechanical device from the centre of the weld nugget. The specimens cut in half were pressed into heated plastic, burnished and branded with an appropriate chemical solution. After the branding operation, the weld nugget between the sheets can be easily seen even without any magnification. To investigate the weld nuggets and their formation between the steel sheets more clearly, macro photographs were taken from weld zones. Figure 4 shows the weld nugget formation between the spot welded AISI 304 and AISI 304 steel sheets.
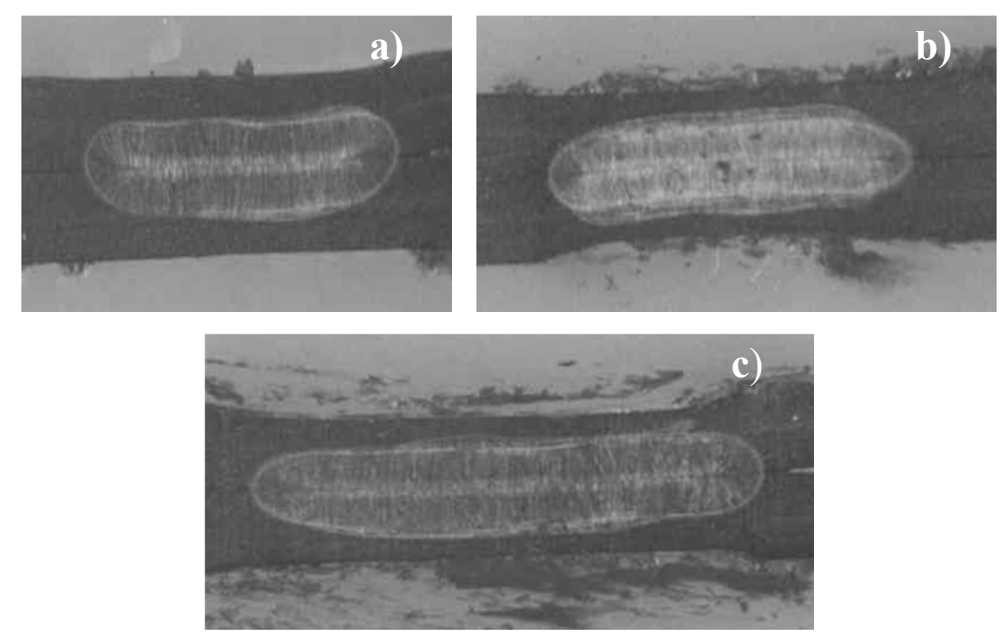

Fig. 4 Weld nugget formation between the spot welded AISI 304 and AISI 304 steel sheets a) $4 \mathrm{~mm}$ nugget diameter, b) $5 \mathrm{~mm}$ nugget diameter, c) $6 \mathrm{~mm}$ nugget diameter 
As seen from Figure 4, the weld nugget between the sheets has a balanced form. Because the same materials were used in the welding operation, there is no unbalanced heat generation; therefore, the formed weld nuggets are equally distributed between the sheets. This result can be expected in the HSLA - HSLA sheet combination because the physical properties of the used materials are the same.

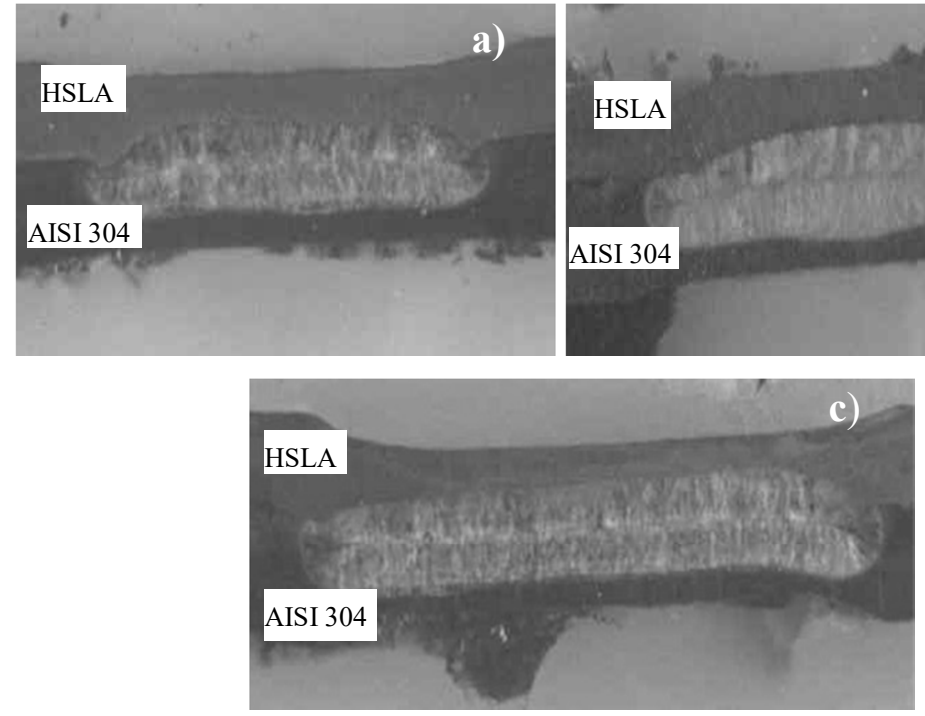

Fig. 5 Weld nugget formation between the spot welded AISI 304 - HSLA steel sheets
a) $4 \mathrm{~mm}$ nugget diameter
b) $5 \mathrm{~mm}$ nugget diameter

c) $6 \mathrm{~mm}$ nugget diameter

Figure 5 shows the weld nugget formation between the spot welded AISI 304 and HSLA steel sheets. From this macro view, it is clearly seen that the weld nugget between the sheets has not formed symmetrically. The nugget has lost its balanced form to the AISI 304 steel sheet side.

The metal materials have the property of electrical resistance, i.e. they oppose the passage of an electric current; this resistance causes heat generation in the metal. In resistance spot welding, the contact area between the sheets has maximum resistance; consequently, the maximum heat is generated in this area. The high amount of generated heat causes the sheets to weld in their contact areas. The sheet thickness and the material type affect the electrical resistance and, thus, the ensuing amount of heat. Equation 1 shows the material resistance to the passage of the current.

$$
R=\frac{\rho \cdot l}{A}
$$

where, $\rho$ is the specific material resistance, $l$ is the current path (sheet thickness), and A is the cross section (electrode diameter).

Because the current path $l$ (sheet thickness) and the electrode diameter are constant during the welding operation, the weld parameter affecting the heat generation is the specific material resistance $\rho$ (material type of sheets). The AISI 304 steel sheet has a higher material resistance than the HSLA steel sheet. Thus, the heat generation is more effective with the AISI 304 steel sheet. As a result of this unbalanced heat generation, the weld nugget has formed asymmetrically between the sheets.

This unexpected nugget formation causes some problems, especially with respect to the mechanical properties of the joint. One of the most important problems can be clearly seen in 
the tensile strength of the welded joint (Figure 3). The highest tensile strength is noted in the AISI 304 - AISI 304 sheet combination which has a symmetrical nugget formation. When different steel sheets are welded to each other by using the resistance spot welding method, the nugget must be formed symmetrically between the sheets. To make sure that this formation type will be obtained, there are some effective methods to be employed. The most effective methods are changes in the electrode tip diameter and in the sheet thickness. By increasing the electrode tip diameter on the side of the sheet with higher resistance or by decreasing the sheet thickness on that side, the current intensity and thus also the resistance of the material can be decreased in the weld zone (Eq. 1).

\section{Conclusion}

In this study, galvanized and austenitic stainless steel sheets were joined to each other by using resistance spot welding. The pre-tests were performed to investigate the effect of the welding current on the nugget diameter. When the values of the welding current are increased, the nugget diameter increases until a critical current value. After that value, the nugget diameter decreases because of excessive melting and splashing. Spot welded specimens were exposed to tensile tests, and the effect of the sheet combination on the maximal tensile strengths was discussed. The AISI 304 - AISI 304 steel sheet combination has the highest tensile strength and the AISI 304 - HSLA steel sheet combination has the lowest tensile strength. According to the results shown in the graphs and according to macroscopic examinations, the nugget formation in the AISI 304 - HSLA steel sheet combination is not formed as balanced. This formation causes some problems related to the mechanical properties of the welded joint. To avoid these problems, some suggestions are given to users of spot welding. The most effective measures to be taken in that case are changes in the electrode tip diameter and in the sheet thickness. By increasing the electrode tip diameter on the side of the sheet with higher resistance or by decreasing the sheet thickness of that sheet, the current intensity and thus also the material resistance can be decreased in the weld zone.

\section{REFERENCES}

[1] Vural, M., Akkus, A., (2004), “On the resistance spot weldability of galvanized interstitial free steel sheets with austenitic stainless steel sheets”, Journal of Material Processing Technology, V. 153-154, pp. 1-6. https://doi.org/10.1016/j.jmatprotec.2004.04.063

[2] Shamsul J B \& Hisyam M M, (2007), "Study of spot welding of austenitic stainless steel type 304", J Appl Sci Res, V. 3(11), pp. 1494-1499.

[3] Satoh, T., Abe, H., Nakaoka, T., Hayata, Y., (1996), "The fatigue life of the spot welded joint under a repeated of $R=-1$ ", Welding in the World, V. 37, PP. 12-15.

Submitted: $\quad 19.4 .2016$

Accepted: $\quad 28.6 .2017$
Ahmet Akkuş, PhD

aakkus@cumhuriyet.edu.tr

Cumhuriyet University, Engineering Faculty,

Mechanical Engineering Department

Sivas - TURKEY 